\title{
Peculiarities of Demonstrative Behavior Manifestations of Teenagers Brought up in Orphanages
}

\author{
Lausan A. Ribakova ${ }^{1} \&$ Gulnara F. Biktagirova ${ }^{1}$ \\ ${ }^{1}$ Kazan (Volga region) Federal University, Kazan, Russia \\ Correspondence: Lausan A. Ribakova, Kazan (Volga region) Federal University, Kazan, Russia. E-mail: \\ valeykin@yandex.ru
}

Received: December 29, 2014

Accepted: January 22, 2015 Online Published: February 11, 2015

doi:10.5539/res.v7n4p148

URL: http://dx.doi.org/10.5539/res.v7n4p148

\begin{abstract}
Theoretical justification and experimental validation of forms and methods applied for psychologicalpedagogical correction of demonstrative behavior of teenagers brought up in orphanages have become the research objective. 127 pupils of orphanages of the Republic of Tatarstan participated in the experiment

To collect the information there were applied two variations of the test for ostentation, methods of mathematical statistics, Student's t-criteria to check hypotheses of mean average precision. The results revealed during the stating experiment showed that teenagers brought up in orphanages have a high level of demonstrative behavior. The majority of respondents are fond of attention; they are emotionally mobile, artistic and inclined to selfdeception.

The level of demonstrative behaviour lowered considerably after the program "Demonstrative behaviout: is it good or bad" aimed at the psychological-pedagogical correction of demonstrative behaviour of teenagers brought up in orphanages was applied at the forming stage of the experiment. Thereafter their demonstrative behaviour started to be of more positive character. There is observed a tendency to the average and low level of demonstrative behaviour of teenagers brought up in orphanages.
\end{abstract}

Keywords: ostentation, demonstrative behaviour, teenagers brought up in orphanages

\section{Introduction}

Teenagers' demonstrative behaviour manifestation is one of the acute social problems of the Russian society at present as the increasing number of teenagers is involved in the use of alcoholic drinks, narcotics, in various subcultures, groupings of antisocial behaviour. Displaying the asocial behaviour the majority of teenagers believe that this is the way to assert themselves, gain authority, and "become adult". Demonstrative behaviour is usually caused by adults' neglectful attitude to teenagers who feel lack of attention in the family where they are disregarded, even forgotten. The similar lack of attention is experienced in particular by children who due to some circumstances have appeared to be in orphanages. These children especially need attention, praise, approval, care.

The traditional policy of education in orphanages is unproductive: it is characterized by mutual rejection, aggression, anxiety, conformism, pupils' low adaptability to life in the society. Declaration of moral revival on the basis of democratic and humanistic values has not become the foundation of teenagers' education in orphanages the goal of which was to make each individual an active participant of social life, capable for selfdevelopment, self-analysis and therefore not displaying demonstrative behaviour.

Although the peculiarities of teenagers' moral development have been revealed quite fully in many researches, there is no complex analysis of teenagers' behaviour disorder problems. Most of the researches deal with primary schoolchildren behaviour, whereas behaviour disorder is the problem of adolescence as well. Numerous works devoted to the issues of behaviour disorder and its correction point to the necessity of its solution. Nowadays the technique of behaviour disorder correction in the educational process built with psychological-pedagogical data in view has not been developed, the problem of psychological-pedagogical correction of demonstrative behaviour of teenagers brought up in orphanages has got very little attention.

The notion "self-presentation" is related to the notion "ostentation". The self-presentation is the presentation of oneself to other people. The issues of demonstrative behaviour as self-presentation were studied by Vilunas 
(1990), Kravchenko (2002), Sokolova-Baush (1999), Shepel (1994), etc. V.M. Shepel defines self-presentation as "the skill to present oneself, to attract attention, to actualize people's interest to one's video- and audioqualities" (Shepel, 1994). J.T. Tedeshi and M. Riess define self-presentation as a deliberate conscious behaviour aimed to produce a certain impression on those around (Tedeshi \& Riess, 1981). Self-presentation according to Schlenker and Weigold (1992) as well as Leary and Kowalski (1990) is a conscious or unconscious process performed by an active subject. They think that self-presentation includes not only the intention to produce a certain impression on others but the demonstration of person's own thoughts and character (Schlenker \& Weigold, 1992).

Thus, "ostentation" as the synonym of "self-presentation" is a deliberate conscious behaviour aimed to produce a certain impression on those around that is revealed in a specific "playing to the opinion of others" behaviour, it is the means of over-estimation and confirmation of Self-image (Kravchenko, 2001).

Proceeding from the definitions of self-presentation and ostentation, we offer the following definition of the notion "demonstrative behavior"-it is the type of behaviour when the person is eager to attract attention and uses all possible means: lie, frivolity, screams shouts etc. Such people are emotional but they are egoistic, do not take their own actions critically; their feelings are shallow. It is really important not to perform such person's whims, not to make the person assure that with the help of such demonstrative actions it is possible to get the desired result, not to give the person any opportunity to manipulate people in such a way. Such behaviour is not the means of protection; it is the way to get some space, self-assertiveness, the way to subject people.

The period of adolescence is of great interest for the researchers of demonstrative behaviour. They have unanimous opinion that ostentation is one of teenagers' peculiar features. Thus, according to the opinion of a psychiatrist A.E. Lichko the demonstrative reaction is one of the most often observed affective reactions in adolescence" (Lichko, 2010).

The main features of teenagers' demonstrative behaviour are limitless egocentricity and thirst for attention. All kinds of interest display, negative or positive, are significant. It can be admiration, surprise, worship, compassion, indignation or hatred of those surrounding, everything but indifference, aloofness, the perspective to be unnoticed.

The desire to stand out is realized in several directions that can interchange or not in case if the teenager is quite satisfied with the result. The first direction - these are actions aimed to get sympathy, respect, and admiration. The second direction is connected with actions, the purpose of which is to get compassion and pity of the surrounding people (Khaliullina \& Biktagirova, 2011).

The third direction is associated with the usage of negative actions to attract attention to oneself. The teenager's behaviour is characterized by bravado, clownish actions, rudeness, impudence, discipline disorders and other deviations of behaviour; the teenager's behaviour is opposed to the society. From our point of view, the most dangerous thing characteristic for this direction is teenager's escape from home and suicidal behaviour (Prikhozhan \& Tolstykh, 1990).

The peculiarities of demonstrative behaviour specific for teenagers brought up in orphanages require a lot of attention and special forms and methods are necessary for psychological-pedagogical correction of their behavior (Valeyeva \& Marghanov, 2010).

In the present research there have been revealed and considered such forms and methods of psychologicalpedagogical correction as logotherapy, play therapy, individual help, art-therapy, psycho-gymnastics, fairy-tale therapy, group correction, social-psychological trainings, (group discussions, exercises-energizers, brain storm, role modeling). All these forms and methods made the basis of the elaborated program "Demonstrative behaviour; is it good or bad?" aimed at the psychological-pedagogical correction of behaviour specific for teenagers brought up in orphanages. Our research is devoted to the approval of this program. Theoretical justification and experimental validation of forms and methods applied for psychology-pedagogical correction of demonstrative behavior of teenagers brought up in orphanages have become the research objective.

\section{Materials and methods}

To reveal the level of testees' ostentation we applied the "Questionnaire of maladaptive traits of character". The level of testees' ostentation was measured from 0 (minimum score) to 90 (maximum score) scores. There were singled out the following levels of ostentation: $0-12$ - a very low level of ostentation (does not like much attention to themselves); 13-31-a low level of ostentation (does not like attention); 32-60 - an average level of ostentation (standard tendency to be pleasant for those surrounding); 61-79-a high level of ostentation (likes attention, emotionally mobile, artistic, tends to self-delusion); 80-90 - a very high level of ostentation (all actions 
are arranged in such a way as to attract attention; likes only positive attention, strong emotiveness, though some emotions are of demonstrative character; likes to show how bad the situation is and think over some unreal diseases; lies very easily and believes in their lies sincerely; has a tendency to self-delusion; artistic).

The test for ostentation offered in the electronic encyclopedia of the azps.ru tests. This test consists of 35 questions, each of which assumes the answer "yes" or "no". There were obtained the following levels at processing: 0-7 points - a low level of ostentation; 8-16 points - an average level of ostentation; 17-29 points-a high level of ostentation; 30-36 points - a very high level of ostentation.

127 pupils of orphanages of the Republic of Tatarstan took part in the research (63 teenagers experimental group, 64 - control group).

\section{Results}

During the stating stage of the experiment there was carried out the test for ostentation taken from the electronic resource and the following results were obtained. 53.6\% (17-29 points) of examinees of the experimental group possess a high level of ostentation; 28.6\% (8-16 points) of respondents have an average level of ostentation and $17.8 \%$ of examinees possess a very high level of ostentation. The obtained data testify that teenagers, brought up in orphanages, have a high level of ostentation. The majority of examinees are artistic and inclined to theatrical effects. Negative experiences are easily forced out, facts are ignored, the appeal to feelings prevails. Usually such people are easygoing, they experience a lot of emotions and they overplay quite often.

In the control group we received similar results. The majority of respondents have a high demonstrative behavior - $56.7 \%$ (17-29 points), $20 \%$ of pupils possess the average level of ostentation and $23.3 \%$ - a very high level of ostentation. The significance value of $t$-criterion makes $t>0.05(t=1.76)$. It means that according to this indicator both groups are equal before the experiment.

According to the "Questionnaire of maladaptive traits of character" results, teenagers of the experimental group, brought up in orphanages, generally have a high level of ostentation (53.6\%), 28.6\% - the average level, $14.8 \%$ of examinees possess a high level and only $3,6 \%$ of examinees possess a low level of ostentation. Thus, the most part of the respondents love attention, are emotionally mobile, artistic and inclined to self-deception.

In the control group the dominating number of respondents have a high level of ostentation $-46.73 \%$, the average level- $-30 \%$, a very high level $-23.3 \%$. The significance value of $t$-criterion makes $t>0.05(t=1.86)$. It means that according to this indicator both groups are equal before the experiment.

Thus, the conducted stating experiment allows to come to the conclusion that the level of demonstrative behavior of teenagers brought up in orphanages is high and, thereat, it has a negative character.

During the forming experiment the program "Demonstrative behaviour: is it good or bad?!" was realized. Such forms and methods as logotherapy, play therapy, individual help, art-therapy, psycho-gymnastics, fairy-tale therapy, group correction, social-psychological trainings, group discussions, exercises-energizers, brain storm, role modeling make the basis of it. This program helped to create such conditions for teenagers which finally stimulate consciousness, self-realization, self-development, ability to make decisions and to be responsible for them, ability to interact with people, adequate self-assessment. The teenager will experience the feeling of being significant, accepted, and successful.

The program includes 3 blocks consisting of 8-10 lessons; each lesson lasts 50-60 minutes. During the forming stage of the experiment, almost each teenager could show their identity, independence of behavior and receive positive emotional spirit.

The control stage of the experiment had the purpose to identify the result of the performed work. At the control stage of our work the following results were obtained. The test for ostentation taken from the electronic resource had the following effect in the experimental group of teenagers brought up in orphanages - the average level became the dominating (8-16 points), 71.4\%. After the experiment the average level increased almost twice that testifies to the efficiency of psychological-pedagogical correction. The high level (17-29 points) of ostentation decreased from $53.3 \%$ to $7,1 \%$. There was observed the recession of ostentation to a low level of approximately $21.5 \%$ of examinees. A very high level of ostentation after the experiment is absent. The obtained data allow to assert the fact that the average level is the prevailing level of ostentation of teenagers brought up in orphanages.

In the control group the results did not change significantly. The dominating number of respondents with a high demonstrative behavior makes $60 \%$, before the experiment it was $56.7 \%$ (17-29 points), the average level of pupils' ostentation decreased from $20 \%$ to $16.7 \%$, and $23.3 \%$ of examinees possess a very high level of ostentation. 
After the experiment, according to the "Questionnaire of maladaptive traits of character" results, teenagers of the experimental group, brought up in orphanages, had an average level of ostentation (it increased from $28.6 \%$ to $57.2 \%$ after the experiment), a high level of ostentation decreased from $53.6 \%$ to $17.8 \%$. A low level of ostentation $(25 \%)$ started to be observed in the group. Thus, most respondents are characterized by a standard tendency to be accepted in the society.

In the control group the number of respondents with a high level of ostentation makes $46.7 \%$ as it was before the experiment. The average level raised from $30 \%$ to $33.3 \%$, a very high level decreased from $17.8 \%$ to $16.7 \%$, and only $3.3 \%$ of examinees have a low level of ostentation.

Thus, according to the results obtained before and after the experiment, it is possible to come to the conclusion that in the experimental group the average level of ostentation prevails after the forming experiment, a high level changed from $43 \%$ to $40 \%$, a very high level decreased to $0 \%$, however, the number of examinees with a low level of ostentation increased from 0 to $13 \%$. In our opinion, it testifies to the efficiency of forms and methods of psychological-pedagogical correction of teenagers' demonstrative behavior. There were no essential changes in the levels in the control group of teenagers.

After carrying out the forming experiment in the experimental group according to Student's t-test, we obtained:

1) The differences between the average values of ostentation on the basis of the test taken from the electronic resource in the experimental group of teenagers brought up in orphanages, before and after the experiment are reliable, as temp $>$ t; $\operatorname{ttd}(\operatorname{temp}=6.64$, at $\operatorname{ttd} 1=2.00 ; \operatorname{ttd} 2=2.66)$ at $\mathrm{p}=0.01$;

2) The differences between the average values of ostentation on the basis of the Questionnaire of maladaptive traits of character in the experimental group of teenagers brought up in orphanages before and after the experiment are reliable, as temp $>\operatorname{t} ; \operatorname{ttd}(\operatorname{temp}=3.11$, at $\operatorname{ttd} 1=2.00 ; \operatorname{ttd} 2=2.66)$ at $\mathrm{p}=0.01$;

There have not been revealed reliable differences in the control group. The differences between the average values of levels of ostentation in the control and experimental groups of teenagers without parental support after the experiment are reliable, as temp $>t$; $\operatorname{ttd}($ temp $=10.6)$ at $\mathrm{p}=0.01$.

\section{Conclusions}

The elaborated program of psychological and pedagogical correction of demonstrative behavior of teenagers brought up in orphanages proved to be effective as the results have shown positive dynamics. The application of the program of psychological and pedagogical correction of demonstrative behavior of teenagers brought up in orphanages allows to decrease the level of teenagers' ostentation that is negatively exposed as demonstrative "nihilism". Thereby, the effective interaction of the teenager with peers and adults, adequate self-assessment, the feeling of oneself as a necessary, significant, and respected member of the society can be achieved.

\section{Acknowledgments}

The work is performed according to the Russian Government Program of Competitive Growth of Kazan Federal University.

\section{References}

Khaliullina, D. R., \& Biktagirova, G. F. (2011). Demonstrative behavior adolescent and school. Successes contemporary science, 8, 198-199.

Khaliullina, D. R., \& Biktagirova, G. F. (2011). Demonstrative behavior adolescent and school. Successes contemporary science, 8, 198-199.

Kravchenko, A. C. (2001). Motivation of demonstrative behavior. Moscow: MSU named after M. V. Lomonosov.

Leary, M. R., \& Kowalski, R. M. (1990). Impression management: A literature review. Psychological Bulletin, 107, 34-47. http://dx.doi.org/10.1037/0033-2909.107.1.34

Lichko, A. E. (2010). Psychopathia and accentuation of teenagers'personality traits. Moscow: Rech (Speech).

Prikhozhan, A. M., \& Tolstykh, N..N. (1990). Children without family. Moscow: Pedagogics.

Schlenker, B. R., \& Weigold, M. F. (1992). Interpersonal processes involving impression regulation and management. Annual Review of $\quad$ Psychology, $43,168$. http://dx.doi.org/10.1146/annurev.ps.43.020192.001025

Shepel, V. M. (1994). Image studies. In Secrets of personal charm. Moscow: Culture and sports.

Sokolova-Baush, E. N. (1999). Self-presentation as a factor to form the impression about the communicator and recipient. Moscow: MSU named after M. V. Lomonosov. 
Tedeshi, J. T., \& Riess, M. (1981). Identities the phenomenal self and laboratory research. In J. T. Tedeshi (Ed.), Impression management theory and social psychological research. N.Y.: Academic Press. http://dx.doi.org/10.1016/B978-0-12-685180-9.50006-3

Valeeva, R. A., \& Marganov, A. G. (2010). Special aspects of orphanage pupils' social and legal competence development. Education and self-development, 6(22), 91-96.

Vilyunas, V. K. (1990). Psychological mechanisms of person's motivation. Moscow: Publishing house of the Moscow University.

\section{Copyrights}

Copyright for this article is retained by the author(s), with first publication rights granted to the journal. This is an open-access article distributed under the terms and conditions of the Creative Commons Attribution license (http://creativecommons.org/licenses/by/3.0/). 